\title{
PENGARUH KESELAMATAN KERJA DAN KESEHATAN KERJA TERHADAP KINERJA KARYAWAN PADA PT. PERKEBUNAN NUSANTARA I PKS PULAU TIGA ACEH TAMIANG
}

\author{
Herizal $^{(1)}$, Wulandari ${ }^{(2)}$ \\ ${ }^{1,2}$ Fakultas Ekonomi Universitas Jabal Ghafur \\ 1'herizal_aprc@yahoo.co.id, ${ }^{2}$ wulandari@yahoo.com
}

\begin{abstract}
ABSTRAK
Penelitian ini berjudul "Pengaruh Keselamatan dan Kesehatan Kerja (K3) Terhadap Kinerja Karyawan Pada PT. Perkebunan Nusantara I PKS Pulau Tiga Aceh Tamiang". Rumusan masalah dalam penelitian ini adalah apakah keselamatan berpengaruh terhadap kinerja Karyawan Pada PT. Perkebunan Nusantara I PKS Pulau Tiga Aceh Tamiang. Apakah kesehatan kerja (K3) berpengaruh terhadap kinerja Karyawan Pada PT. Perkebunan Nusantara I PKS Pulau Tiga Aceh Tamiang. Tujuan penelitian ini adalah untuk mengetahui keselamatan berpengaruh terhadap kinerja Karyawan dan untuk mengetahui kesehatan kerja (K3) berpengaruh terhadap kinerja Karyawan Pada PT. Perkebunan Nusantara I PKS Pulau Tiga Aceh Tamiang.Penelitian ini mengambil sampel 31 orang karyawan PT. Perkebunan Nusantara I PKS Pulau Tiga Aceh Tamiang. Data hasil penelitian dianalisis dengan peralatan statistik sederhana antara lain distribusi frkuensi, persentase dan rata-rata. Untuk mengukur kehandalan variabel dalam kuesioner diterapkan analisis Cronbach Aalpha pada taraf signifikansi 0,5. Untuk membuktikan hipotesis lebih lanjut digunakan peralatan Pearson' Correlation, Linear Regression, dan t-Test. Hasil penelitian ini menunjukan bahwapersamaan regresi linear berganda di atas dapat dijelaskan bahwa nilai constantas sebesar 4,722 artinya jika keselamatan kerja (X1) dan kesehatan kerja (X2) dianggap constan, maka kinerja Karyawan Pada PT. Perkebunan Nusantara I PKS Pulau Tiga Aceh Tamiang adalah 4,433sebagai nilai constanta atau nilai variabel kinerja karyawan (Y). Nilai koefisien regresi keselamatan kerja sebesar 0,280 dapat diartikan bahwa setiap $1 \%$ kenaikan kesehatan kerja yang baik $\left(\mathrm{X}_{1}\right)$ akan meningkatkan kinerja karyawan Pada PT. Perkebunan Nusantara I PKS Pulau Tiga Aceh Tamiang sebesar 28,0\%. Ini artinya terjadi peningkatan keselamatan kerja Pada PT. Perkebunan Nusantara I PKS Pulau Tiga Aceh Tamiang. Hubungan variabel dependen dan independen yaitu masing-masing variabel keselamatan kerja $\left(\mathrm{X}_{1}\right)$ dan kesehatan kerja $\left(\mathrm{X}_{2}\right)$ terhadap kinerja karyawan Pada PT. Perkebunan Nusantara I PKS Pulau Tiga Aceh Tamiang dengan indeks korelasi sebesar 93,6\% ini berarti hubungan tersebut sangat kuat.
\end{abstract}

Kata Kunci : Keselamatan, Kesehatan Kerja dan Kinerja 
Jurnal Sosial Humaniora Sigli (JSH)

p ISSN : 2615-3688

$e$ ISSN : 2716-0270

http : //journal.unigha.ac.id/index.php/JSH

\section{Pendahuluan}

\section{Latar Belakang Penelitian}

Dalam menjalankan suatu bisnis perusahaan membutuhkan berbagai sumber daya, seperti modal, material dan mesin.Perusahaan juga membutuhkan sumber daya manusia, yaitu para karyawan. Sumber daya manusialah yang paling penting dan sangat menentukan, karena tanpa sumber daya manusia yang bagus maka perusahaan itu tidak akan berjalan dengan baik pula. Karyawan merupakan sumber daya yang penting bagi perusahaan, karena memiliki akal, bakat, tenaga, keinginan, pengetahuan, perasaan, dan kreatifitas yang sangat dibutuhkan oleh perusahaan untuk mencapai visi dan misi perusahaan.

Peranan sumber daya manusia dalam proses produksi banyak diperbincangkan, sehingga berbagai cara diusahakan untuk mengembangkan kerja dan meningkatkan taraf hidup manusia. Peranan manajemen perusahaan dalam mengarahkan, membimbing serta menciptakan iklim industri yang sehat kepada perusahaan adalah untuk menciptakan struktur ekonomi yang lebih kuat dan seimbang.Hal ini sejalan dengan pengertian manajemen personalia itu sendiri yaitu seni dan ilmu memperoleh, memajukan dan memanfaatkan tenaga kerja sedemikian rupa sehingga tujuan organisasi dapat direalisir secara berdaya guna dan berhasil guna dan adanya kegairahan kerja dari para tenaga kerja.

Seiring perkembangan ilmu pengetahuan dan teknologi canggih serta munculnya inovasi-inovasi baru dibidang teknik produksi, telah mendorong perusahaan untuk meningkatkan pengetahuan dan keterampilan sumber daya manusianya, agar dapat menghasilkan produk yang berkualitas tinggi.Sumber daya manusia sebagai karyawan tidak lepas dari masalah yang berkaitan dengan keselamatan kerja dan kesehan kerja sewaktu bekerja, dengan menjamin keselamatan kerja dan kesehatan kerja dapat menumbuhkan semangat kerja pada karyawan.

Perusahaan berupaya untuk meningkatkan kinerja seluruh karyawannya agar mampu bersaing dengan perusahaan lain karena dapat menghasilkan suatu barang atau jasa dengan cara yang lebih efisiensi. Kinerja merpakan tingkat keberhasilan seseorang secara keseluruhan dalam periode tertentu didalam melaksanakan tugas dibanding dengan berbagai kemungkinan seperti standart hasil kerja, target, sasaran atau kriteria yang telah ditentukan terlebih dahulu dan telah disepakati bersama. Hal ini dapat tercapai apabila perusahaan selalu memperhatikan faktor keselamatan kerja dan kesehatan kerja karena hal ini akan dapat meningkatkan kinerja karyawan.

Keselamatan Kerja dan Kesehatan Kerja adalah suatu program yang dibuat oleh pemerintah yang harus dipatuhi dan dilaksanakan pengusaha maupun pekerja sebagai upaya mencegah timbulnya kecelakaan akibat kerja dan penyakit akibat kerja dengan cara mengenali hal yang berpotensi menimbulkan kecelakaan dan penyakit akibat kerja serta tindakan antisipatif apabila terjadi kecelakaan dan penyakit akibat kerja. Tujuannya adalah untuk menciptakan tempat kerja yang nyaman, dan sehat sehingga dapat menekan serendah mungkin resiko kecelakaan dan penyakit.Perhatian terhadap kesehatan pekerjaan pada mulanya lebih menekankan pada masalah keselamatan kerja yaitu perlindungan pekerjaan dari kerugian atau luka yang disebabkan oleh kecelakaan berkaitan dengan kerja.Kemudian seiring dengan perkembangan industri, perusahaan 
Jurnal Sosial Humaniora Sigli (JSH)

p ISSN : 2615-3688

$e$ ISSN : 2716-0270

http : //journal.unigha.ac.id/index.php/JSH

mulai memperhatikan kesehatan pekerja dalam arti luas yaitu terbebasnya pekerjaan dari kesakitan fisik maupun psikis.

Setiap pekerjaan selalu mengandung potensi resiko bahaya dalam bentuk kecelakaan dan penyakit kerja.Besarnya potensi kecelakaan tersebut tergantung dari jenis tata ruang dan lingkungan bangunan serta kualitas manajemen dan tenagatenaga pelaksana. Kasus-kasus kecelakaan dan penyakit kerja di dunia, Indonesia masih cukup besar, baik di kota maupun di desa, baik disektor industri dan jasa-jasa maupun juga disektor pertanian. Kecelakaan dan penyakit kerja tersebut mengakibatkan banyak pekerja meninggal atau cacat, sehingga tidak mampu lagi bekerja. Dengan kondisi fisik yang menurun atau menjadi tidak mampu lagi untuk bekerja, penghasilan pun akan berkurang atau menjadi tidak ada.

Terjadinya kecelakaan atau penyakit kerja dan dapat berakibat kematian, atau karyawan bisa mengalami cacat atau sakit untuk sementara dan tidak bisa bekerja, maka karyawan yang bersangkutan tidak mampu lagi bekerja dengan baik atau tingkat produktivitas kerjanya akan mengalami penurunan dibanding waktu sehat. Oleh sebab itu perlu sistem pemberian kompensasi akibat kecelakaan dan penyakit kerja, karena itu akan menumbuhkan semangat kerja untuk meningkatkan kinerja karyawan.

PT. Perkebunan Nusantara I PKS Pulau Tiga Aceh Tamiang merupakan pabrik kelapa sawit yang menggunakan banyak tenaga kerja.Profil PerusahaanPTP. I PKS Kebun Pulau Tiga, Aceh Tamiang Provinsi Nanggroe Aceh Darussalam adalah sebagai berikut:

Dengan nama perusahaan PTP I PKS Pulau Tiga. Alamat Desa Perkebunan Pulau Tiga. Kota Aceh Tamiang. Provinsi
Nanggroe Aceh Darussalam. Komoditi minyak sawit.

Pada proses produksinya menggunakan mesin-mesin yang dapat menimbulkan potensi bahaya yang dapat mengancam keselamatan dan kesehatan pekerjanya, diantaranya menggunakan mesin berat yang dapat berdampak pada keselamatan pekerja. Pengabaian aspek keselamatan dan kesehatan kerja dalam suatu proses produksi/industri akan dapat menurunkan kinerja dan bahkan mengakibatkan kerugian yang dampaknya bukan saja bagi pengusaha tetapi juga para pekerjanya.

Keputusan dalam menggunakan peralatan mesin berat yang berpengaruh pada keselamatan dan kesehatan karyawan merupakan hal yang sangat penting untuk menjaga kinerja karyawan. Permasalahan akan semakin banyak apabila PT. Perkebunan Nusantara I PKS Pulau Tiga Aceh Tamiang menggunakan alat atau mesim besar, karena PT. Perkebunan Nusantara I PKS Pulau Tiga Aceh Tamiang harus dapat menjamin penggunaan alat-alat kerja dalam meningkatan produk dan juga harus dapat menjamin keselamatan dan kesehatan dari karyawan, sebab kecelakaan maupun insiden yang tidak diinginkan dapat menyebabkan cedera, gangguan produksi akibat hilangnya jam kerja, dan menurunnya kinerja karyawan.Kesehatan Kerja dan Keselamatan Kerja apabila telah terpenuhi maka akan menyebabkan karyawan bekerja dengan segenap kemampuannya, sehingga kinerja meningkat. Untuk mengetahui seberapa besar pengaruh kesehatan dan keselamatan kerja terhadap kinerja karyawan, sehingga penulis tertarik untuk mengadakan penelitian lebih lanjut dengan judul :"Pengaruh Keselamatan Kerja dan Kesehatan Kerja Terhadap Kinerja 
Jurnal Sosial Humaniora Sigli (JSH)

p ISSN : 2615-3688

$e$ ISSN : 2716-0270

http : //journal.unigha.ac.id/index.php/JSH

\section{Karyawan Pada PT. Perkebunan Nusantara I PKS Pulau Tiga Aceh Tamiang".}

\section{Tujuan Penelitian}

Adapun yang menjadi tujuan dalam penelitian ini adalah: Untuk mengetahui pengaruh keselamatan dan kesehatan kerja terhadap kinerja Karyawan Pada PT. Perkebunan Nusantara I PKS Pulau Tiga Aceh Tamiang.

\section{Tinjauan Pustaka}

\section{Pengertian Keselamatan Kerja}

Menurut Bangun Wilson (2012:377) Keselamatan Kerja adalah perlindungan atas keamanan kerja yang dialami pekerja baik fisik maupun mental dalam lingkungan pekerjaan. Manajemen Keselamatan kerja meliputi perlindungan karyawan dari kecelakaan di tempat kerja sedangkan, kesehatan merujuk kepada kebebasan karyawan dari penyakit secara fisik maupun mental.

Keselamatan kerja menurut Mondy dan Noe (2009:360) adalah perlindungan karyawan dari luka-luka yang disebabkan oleh kecelakaan yang terkait dengan pekerjaan.Resiko keselamatan merupakan aspek-aspek dari lingkungan kerja yang dapat menyebabkan kebakaran, ketakutan aliran listrik, terpotong, luka memar, keseleo, patah tulang, kerugian alat tubuh, penglihatan dan pendengaran.

\section{Pengertian Kesehatan Kerja}

Menurut Sedarmayanti (2010:214), menyebutkan bahwa kesehatan merupakan sebuah pemeliharaan dimana suatu kondisi untuk menjaga kesejahteraan fisik dengan meningkatkan kondisi mental, loyalitas dan kondisi fisik para pegawai agar mereka tetap ingin bekerja sampai mereka pension.

Sedangkan pendapat Mangkunegara (2010:161),kesehatan kerja menunjukkan pada kondisi yang bebas dari gangguan fisik, mental, emosi atau rasa sakit yang disebabkan oleh lingkungan kerja. Resiko kesehatan merupakan faktorfaktor dalam lingkungan kerja yang bekerja melebihi periode waktu yang ditentukan, lingkungan yang dapat membuat stress emosi atau gangguan fisik.

Menurut Mangkunegara (dalam Sayuti, 2013:196) kesehatan kerja adalah kondisi yang bebas dari gangguan fisik, mental emosi, atau rasa sakit yang disebabkan oleh lingkungan kerja.Sedangkan keselamatan kerja adalah pengawasan terhadap orang, mesin, material, dan metode yang mencakup lingkungan kerja agar supaya pekerja tidak mengalami cedera.

\section{Pengertian Kinerja}

Istilah kinerja berasal dari job performance atau actual performance (prestasi kerja atau prestasi sesungguhnya yang dicapai oleh seseorang), atau juga hasil kerja secara kualitas dan kuantitas yang ingin dicapai oleh seorang pegawai dalam melaksanakan tugasnya sesuai dengan tanggung jawab yang diberikan kepadanya (Mangkunegara, 2010 : 67).

Arti penting dari kinerja adalah hasil kerja yang dapat dicapai seseorang atau sekelompok orang dalam suatu organisasi, sesuai dengan wewenang dan tanggung jawab masing-masing dalam upaya mencapai tujuan organisasi bersangkutan secara legal, tidak melanggar hukum dan sesuai dengan moral maupun etika (Sedarmayanti 2009: 260).

Menurut Sugiyono (2010:46) Kinerja merupakan perbandingan hasil kerja yang dicapai oleh pegawai dengan standar yang 
Jurnal Sosial Humaniora Sigli (JSH)

p ISSN : 2615-3688

$e$ ISSN : 2716-0270

http : //journal.unigha.ac.id/index.php/JSH

telah ditentukan. Unit sumber daya manusia dalam suatu organisasi seharusnya berperan untuk menganalisis dan membantu memperbaiki masalah-masalah dalam pencapaian kinerja.

\section{Metode Penelitian}

\section{Ruang Lingkup Penelitian}

Ruang Lingkup dalam penelitian ini adalah pengaruh keselamatan dan kesehatan kerja,terhadap kinerja karyawan pada PT. Perkebunan Nusantara I PKS Pulau Tiga Aceh Tamiang.

\section{Lokasi dan Objek Penelitian}

Lokasi penelitian inidilakukan pada PT. Perkebunan Nusantara I PKS Pulau Tiga Aceh Tamiang.Objek dalam penelitian ini yang berhubungan dengan keselamatan dan kesehatan kerja,terhadap kinerja.

\section{Populasi dan Sampel}

Populasi

Populasi adalah keseluruhan objek penelitian (Arikunto, 2006:130). Jadi populasi dalam penelitian ini adalah seluruh karyawan yang bekerja pada PT. Perkebunan Nusantara I PKS Pulau Tiga Aceh Tamiang, yaitu berjumlah 122 orang.

\section{Sampel}

Menurut Arikunto, (2006:134), jumlah sampel yang akan diambil, adalah apabila subjek kurang dari 100 orang, lebih baik diambil semua, akan tetapi jika jumlah subjeknya besar maka jumlah sampel yang akan diambil adalah antara $10-15 \%$ atau $20-$ 25\% (Arikunto 2006:134).Penulis mengambil sampel dari penelitian adalah sebagian karyawan di PT. Perkebunan Nusantara I PKS Pulau Tiga Aceh Tamiangsebanyak 31 orang atau $25 \%$ sebagian dari jumlah populasi.

\section{Tekhnik Pengumpulan Data}

a. Kuesioner, yaitu pengumpulan data yang dilakukan oleh penulis dengan cara menyebarkan daftar pernyataan yang telah di format khusus kepada responden yang sifatnya tertutup, yang pilihan jawabannya dengan menggunakan skala likert (1-5).

b. Wawancara, yaitu pengumpulan data yang dilakukan oleh penulis dengan cara melakukan tanya jawab secara langsung dengan pihak-pihak yang bersangkutan guna mendapatkan data dan informasi untuk mendukung penelitian ini.

c. Studi pustaka, yaitu pengumpulan data yang dilakukan oleh penulis dengan mengumpulkan data yang bersumber dari literatur-literatur, bahan kuliah, dan hasil penelitian lainnya yang ada hubungannya dengan objek penelitian.

\section{Skala Pengukuran}

Skala pengukuran yang di gunakan adalah skala likert (Liker scale). Skala likert pada dasarnya adalah skala ordinal karena menunjukan tingkat data. Skala likert yang digunakan dalam penelitian ini adalah skala lima poin berkisar 1 sampai 5. Pemberian skala untuk memberikan bobot atau skor terhadap masing-masing tingkat kesetujuan sebagai alternatif pilihan jawaban pada masing-masing pernyataan, seperti terlihat dalam Table III-1 berikut. 
Jurnal Sosial Humaniora Sigli (JSH)

p ISSN : 2615-3688

$e$ ISSN : 2716-0270

http : //journal.unigha.ac.id/index.php/JSH

Alternatif pilihan jawaban kuesioner

berdasarkan skor

\begin{tabular}{|c|c|c|}
\hline Pilihan & Keterangan & Score \\
\hline STS & Sangat Tidak Setuju & 1 \\
\hline TS & Tidak Setuju & 2 \\
\hline KS & Kurang Setuju & 3 \\
\hline S & Setuju & 4 \\
\hline SS & Sangat Setuju & 5 \\
\hline
\end{tabular}

\section{Peralatan Analisis Data}

Metode analisis data yang digunakan dalam penelitian ini adalah Regresi Berganda yang diolah melalui komputer dengan menggunakan program SPSS. Regresi linear berganda dapat dirumuskan secara berikut(Sugiyono, 2009:21) :

$\mathrm{Y}=\alpha+\beta_{1} \mathrm{X}_{1}+\beta_{2} \mathrm{X}_{2}+\mathrm{e}$

Dimana:

$\mathrm{Y}=$ Kinerja Karyawan

$\mathrm{a}=$ Konstanta

$\beta=$ Parameter (koefisien regresi)

$\mathrm{X}_{1}=$ Keselamatan
$\mathrm{X}_{2}=$ Kesehatan kerja

$\mathrm{e}=$ error

\section{Hasil Penelitian Dan Pembahasan}

Uji Reliabilitas

Uji reliabilitaskuisioner dinilai dengan menggunakan croanbach alpha. Croanbach alpha menerjemahkan kolerasi antara skala yang dirancang dengan seluruh skala yang diukur, dan juga dapat mengukur objek yang sama. Tingkat koefisien yang dinyatakan handal sebesar 0,60, sedangkan reliabilitas dibawah tersebut dianggap kurang reliabel.

Tabel 4.6

Reliabilitas Variabel Penelitian Alpha

\begin{tabular}{|l|l|c|c|c|}
\hline No & \multicolumn{1}{|c|}{ Variabel } & $\begin{array}{c}\text { Item } \\
\text { Variabel }\end{array}$ & Nilai Alpha & Kehandalan \\
\hline 1. & Keselamatan Kerja $\left(\mathrm{X}_{1}\right)$ & 5 & 0,719 & Handal \\
\hline 2. & Kesehatan Kerja $\left(\mathrm{X}_{2}\right)$ & 5 & 0,693 & Handal \\
\hline 3. & Kinerja Kerja (Y) & 5 & 0,620 & Handal \\
\hline
\end{tabular}

Sumber : Data Primer Diolah, (2019)

Berdasarkan tabel di atas dapat diketahui bahwa alpha untuk masing-masing variabel yaitu variabel keselamatan kerja $\left(\mathrm{X}_{1}\right)$ diperoleh nilai alpha sebesar 0,719 artinya keselamatan dapat dikatakan handal dapat memenuhi syarat reliabilitas atau dapat memberikan indikasi bahwa alat ukur tersebut mendapat kehandalan. Variabel kesehatan kerja $\left(\mathrm{X}_{2}\right)$ diperoleh nilai alpha

sebesar 0,693 artinya kesehatan dapat dikatakan handal dapat memenuhi syarat reliabilitas atau dapat memberikan indikasi bahwa alat ukur tersebut mendapat kehandalan.

Variabel kinerja karyawan (Y) diperoleh nilai alpha sebesar 0,620 artinya keselamatan dapat dikatakan handal dapat memenuhi syarat reliabilitas atau dapat 
Jurnal Sosial Humaniora Sigli (JSH)

p ISSN : 2615-3688

$e$ ISSN : 2716-0270

http : //journal.unigha.ac.id/index.php/JSH

memberikan indikasi bahwa alat ukur tersebut mendapat kehandalan. Dengan demikian pengaruh pengukuran reliabilitas terhadap variabel penelitian menunjukkan bahwa pengukuran kehandalan memenuhi syarat reliabilitas atau dengan kata lain bahwa kuesioner ini reliabel sebagai instrumen penelitian.

\section{Uji Validitas}

Penentuan validitas didasarkan atas perbandingan nilai kolerasi (r) yang diperoleh antara skor item dengan skor total

Tabel 4.5

Hasil Uji Validitas

\begin{tabular}{|c|c|c|c|c|}
\hline Variabel & Pertanyaan & Koefisien Korelasi & Nilai Kritis $=\mathbf{5 \%}$ & Ket \\
\hline \multirow{5}{*}{$\mathrm{X}_{1}$} & $\mathrm{X} 1.1$ & 0,737 & 0,344 & Valid \\
\hline & $\mathrm{X} 1.2$ & 0,652 & 0,344 & Valid \\
\hline & $\mathrm{X} 1.3$ & 0,741 & 0,344 & Valid \\
\hline & $\mathrm{X} 1.4$ & 0,311 & 0,344 & Valid \\
\hline & $\mathrm{X} 1.5$ & 0,339 & 0,344 & Valid \\
\hline \multirow{5}{*}{$X_{2}$} & $\mathrm{X} 2.1$ & 0,557 & 0,344 & Valid \\
\hline & $\mathrm{X} 2.2$ & 0,567 & 0,344 & Valid \\
\hline & $\mathrm{X} 2.3$ & 0,510 & 0,344 & Valid \\
\hline & $\mathrm{X} 2.4$ & 0,507 & 0,344 & Valid \\
\hline & $\mathrm{X} 2.5$ & 0,381 & 0,344 & Valid \\
\hline \multirow{5}{*}{$\mathrm{Y}$} & Y1 & 0,557 & 0,344 & Valid \\
\hline & $\mathrm{Y} 2$ & 0,624 & 0,344 & Valid \\
\hline & Y3 & 0,321 & 0,344 & Valid \\
\hline & Y4 & 0,465 & 0,344 & Valid \\
\hline & Y5 & 0,321 & 0,344 & Valid \\
\hline
\end{tabular}

Sumber : Data Primer Diolah, (2019)

Dari tabel IV-I diatas dapat disimpulkan bahwa semua indikator variabel dependen dan independen dapat dinyatakan valid karena $r_{\text {hitung }}>r_{\text {tabel. }}$. item, dengan nilai kritis kolerasi produck moment. Apabila nilai kolerasi dihitung lebih besar bila dibandingkan dengan nilai produck moment pada tingkat keyakinan 95\% dapat dinyatakan item-item pertanyaan tersebut valid, ataupun dengan melihat hasil $r$ hitung $>\quad r$ tabeldinyatakan valid dan sebaliknya hasil $\mathrm{r}_{\text {hitung }}<\mathrm{r}_{\text {tabel }}$ dinyatakan tidak valid. Hasil perhitungan dengan menggunakan SPSS 0.17 adalah sebagai berikut : 
Jurnal Sosial Humaniora Sigli (JSH)

$p$ ISSN : 2615-3688

$e$ ISSN : 2716-0270

http : //journal.unigha.ac.id/index.php/JSH

sesungguhnya akan mengikuti garis adalah sebagai sebagai berikut :

diagonalnya. Hasil olahan data diperoleh

Gambar IV.1

Grafik Uji Normalitas

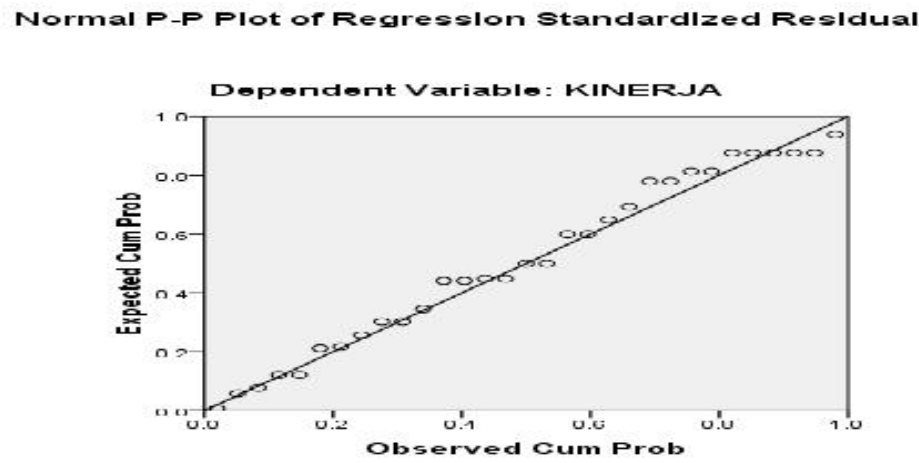

Dari gambar IV.1 di atas dapat disimpulkan bahwa grafik tersebut berdistribusi normal karena terletak disekitar garis(tidak terpisah jauh dari garis diagonal), dan data normal jika garis yang menggambarkan data sesungguhnya akan mengikuti garis diagonalnya.

\section{Uji Multikolinearitas}

Untuk mendeteksi ada atau tidaknya multikolinearitas di dalam model regresi adalah mempunyai nilai VIF di bawah atau kurang dari nilai $10(<10)$. Hasil pengolahan data sebagai berikut :

Tabel 4.8

Nilai VIF Variabel Bebas

\begin{tabular}{|l|c|l|}
\hline \multicolumn{1}{|c|}{ Variabel Bebas } & VIF & \multicolumn{1}{c|}{ Keterangan } \\
\hline Variabel Keselamatan Kerja $\left(\mathrm{X}_{1}\right)$ & 1.845 & Non Multikolinearitas \\
\hline Variabel Kesehatan Kerja $\left(\mathrm{X}_{2}\right)$ & 1.845 & Non Multikolinearitas \\
\hline
\end{tabular}

Sumber : Data Primer Diolah, (2019)

Dari tabel di atas dapat di simpulkan

bahwa tidak ada multikolinieritas karena

\section{Uji Hesterokedestisitas}

mempunyai nilai VIF di bawah atau kurang dari nilai $10(<10)$.

Deteksi ada tidaknya heteroskedastisitas dapat dilakukan dengan melihat ada tidaknya pola tertentu pada grafik scatter plot. Jika ada pola tertentu, seperti titik-titik 
Jurnal Sosial Humaniora Sigli (JSH)

p ISSN : 2615-3688

$e$ ISSN : 2716-0270

http : //journal.unigha.ac.id/index.php/JSH

yang ada membentuk pola tertentu yang teratur (bergelombang, melebar kemudian menyempit), maka telah terjadi heteroskedastisitas.Jika tidak ada pola yang jelas, maka tidak terjadi heteroskedastisitas. Hasil olahan data sebagai berikut :

\section{Grafik Uji Heterokedastisitas}

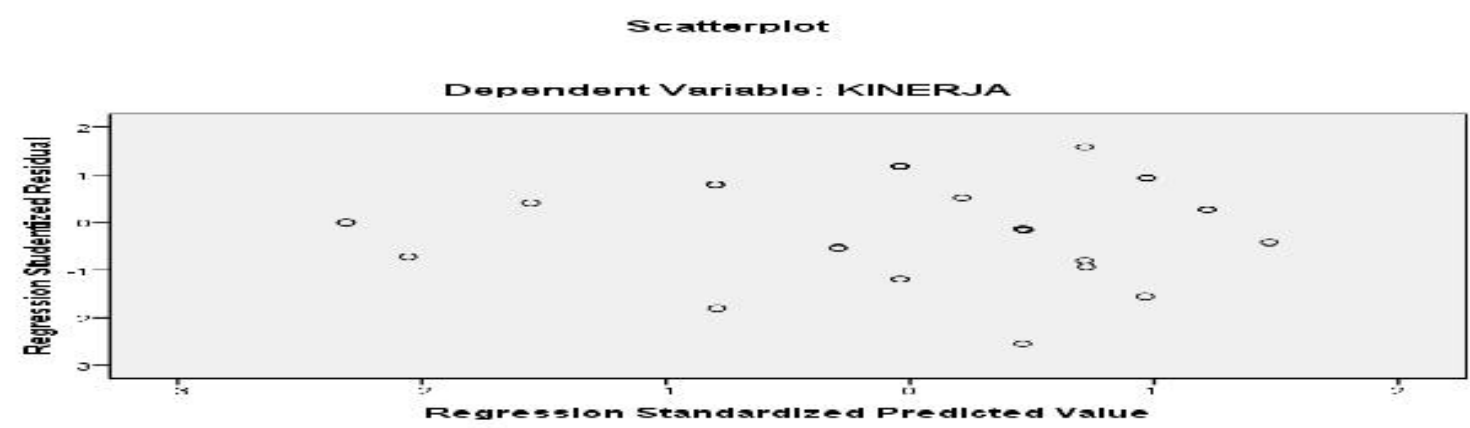

Dari gambar diatas terlihat bahwa tidak terjadinya heterokedastisitas karena tidak terdapat pola tertentu pada grafik, seperti mengumpul ditengah, menyempit kemudian melebar atau sebaliknya.

\section{Hasil Regresi Linear Berganda}

Regresi linear berganda digunakan untuk melihat sejauh mana pengaruh variabel independen terhadap variabel dependen, dimana hasil perhitungannya adalah sebagai berikut:

Tabel 4.9

Pengaruh Masing-masing Variabel Independen Terhadap Variabel Dependen

\begin{tabular}{|c|c|c|c|c|c|c|}
\hline Nama Variabel & B & $\begin{array}{c}\text { Standar } \\
\text { Erro }\end{array}$ & Beta & $\mathbf{t}_{\text {hitung }}$ & $\mathbf{t}_{\text {tabel }}$ & Sign \\
\hline Constanta & 4,433 & 1,295 & & 3,422 & 1,699 & 0,002 \\
\hline Keselamatan Kerja $\mathrm{X}_{1}$ ) & 0,280 & 0,073 & 0,348 & 3,842 & 1,699 & 0,001 \\
\hline Kesehatan Kerja $\left(\mathrm{X}_{2}\right)$ & 0,554 & 0,076 & 0,664 & 7,333 & 1,699 & 0,000 \\
\hline \multirow{2}{*}{\multicolumn{2}{|c|}{$\begin{array}{ll}\text { Koefisien Korelasi (R) } & \\
\text { Koefisien Determinasi } & \left(\mathrm{R}^{2}\right)\end{array}$}} & \multicolumn{5}{|l|}{$=0,936$} \\
\hline & & \multicolumn{5}{|l|}{$=0,875$} \\
\hline \multicolumn{2}{|l|}{ Adjustes R Squares } & \multicolumn{5}{|l|}{$=0,867$} \\
\hline \multicolumn{2}{|l|}{$\mathrm{F}_{\text {hitung }}$} & \multicolumn{5}{|l|}{$=98,409$} \\
\hline \multicolumn{2}{|l|}{$\mathrm{F}_{\text {tabel }}$} & $=2,70$ & & & & \\
\hline \multicolumn{2}{|l|}{ Sign F } & \multicolumn{5}{|l|}{$=0,000$} \\
\hline
\end{tabular}

Sumber : Data Primer Diolah, (2019) 
Jurnal Sosial Humaniora Sigli (JSH)

p ISSN : 2615-3688

$e$ ISSN : 2716-0270

http : //journal.unigha.ac.id/index.php/JSH

Dari persamaan regresi linear berganda di atas dapat dijelaskan bahwa nilai constantas sebesar 4,722 artinya jika keselamatan kerja (X1) dan kesehatan kerja (X2) dianggap constan, maka kinerja Karyawan Pada PT. Perkebunan Nusantara I PKS Pulau Tiga Aceh Tamiang adalah 4,433sebagai nilai constanta atau nilai variabel kinerja karyawan (Y).

Nilai koefisien regresi keselamatan kerja sebesar 0,280 dapat diartikan bahwa setiap $1 \%$ kenaikan kesehatan kerja yang baik $\left(\mathrm{X}_{1}\right)$ akan meningkatkan kinerja karyawan Pada PT. Perkebunan Nusantara I PKS Pulau Tiga Aceh Tamiang sebesar $28,0 \%$. Ini artinya terjadi peningkatan keselamatan kerja Pada PT. Perkebunan Nusantara I PKS Pulau Tiga Aceh Tamiang.

Nilai koefisien regresi kesehatan sebesar 0,554 dapat diartikan bahwa setiap $1 \%$ kenaikan kesehatan $\left(\mathrm{X}_{2}\right)$ akan meningkatkan kinerja karyawan Pada PT. Perkebunan Nusantara I PKS Pulau Tiga Aceh Tamiang 55,4\%. Ini berarti terjadi peningkatan kinerja karywan Pada PT. Perkebunan Nusantara I PKS Pulau Tiga Aceh Tamiang.
Berdasarkan hasil analisis di atas dapat disimpulkan bahwa dari kedua variabel yang diteliti ternyata variabe keselamatan dan kesehatan sama-sama berpengaruh terhadap kinerja karyawan Pada PT. Perkebunan Nusantara I PKS Pulau Tiga Aceh Tamiang.

Hubungan variabel dependen dan independen yaitu masing-masing variabel keselamatan kerja $\left(\mathrm{X}_{1}\right)$ dan kesehatan kerja $\left(\mathrm{X}_{2}\right)$ terhadap kinerja karyawan Pada PT. Perkebunan Nusantara I PKS Pulau Tiga Aceh Tamiang dengan indeks korelasi sebesar 93,6\% ini berarti hubungan tersebut sangat kuat..

\section{Pembuktian Hipotesis}

\subsubsection{Pembuktian Secara Simultan (Uji} F)

Uji $F$ dilakukan untuk melihat pengaruh variabel independen terhadap variabel dependen secara bersama-sama (secara simultan). Pembuktiannya dapat dijelaskan sebagai berikut:

Tabel 4.10

Hasil Analisis Uji F

\begin{tabular}{|c|l|c|c|c|c|c|c|}
\hline \multicolumn{2}{|c|}{ Model } & Sum of & Df & Mean & F & F $_{\text {tabel }}$ & Sign \\
\hline \multirow{3}{*}{1} & Regressio & 36,487 & 2 & 18,243 & 98.409 & 2,70 & 0,000 \\
\cline { 2 - 8 } & Residual & 5,191 & 28 & 0,185 & & 2,70 & \\
\cline { 2 - 8 } & Total & 41,677 & 30 & & & 2,70 & \\
\hline
\end{tabular}

Sumber : Data Primer Diolah, (2019)

\subsubsection{Pembuktian Secara Parsial (Uji t)}

Uji t digunakan untuk melihat pengaruh variabel independen terhadap variabel dependen secara individu / parsial. Hasil olahan data terlihat pada tabel IV-12 berikut ini: 
Jurnal Sosial Humaniora Sigli (JSH)

p ISSN : 2615-3688

$e$ ISSN : 2716-0270

http : //journal.unigha.ac.id/index.php/JSH

Tabel 4.11

Hasil Analisis Uji t

\begin{tabular}{|c|c|c|c|c|c|c|c|}
\hline \multirow{2}{*}{\multicolumn{2}{|c|}{ Model }} & \multicolumn{2}{|c|}{$\begin{array}{l}\text { Unstandarized } \\
\text { Coefficients }\end{array}$} & \multirow{2}{*}{$\begin{array}{c}\begin{array}{c}\text { Unstandarized } \\
\text { Coefficients }\end{array} \\
\text { Beta } \\
\end{array}$} & \multirow[t]{2}{*}{$\mathbf{t}_{\text {hitung }}$} & \multirow[t]{2}{*}{$\mathbf{t}_{\text {tabel }}$} & \multirow[t]{2}{*}{ Sig } \\
\hline & & B & Std.Error & & & & \\
\hline \multirow{3}{*}{1} & Contant & 4,433 & 1,295 & & 3,422 & 1,699 & 0,002 \\
\hline & Keselamatan Kerja & 0,280 & 0,073 & 0,348 & 3,842 & 1,699 & 0,001 \\
\hline & Kesehatan Kerja $\left(\mathrm{X}_{2}\right)$ & 0,554 & 0,076 & 0,664 & 7,333 & 1,699 & 0,000 \\
\hline
\end{tabular}

Sumber : Data Primer Diolah, (2019)

a. Variabel keselamatan kerja $\left(\mathrm{X}_{1}\right)$ diperoleh $t_{\text {hitung }} 3,842>t_{\text {tabel }}$ 1,699 sehingga Hipotesis Nol (Ho) ditolak dan Hipotesis Alternatif (Ha) diterima. Dari hasil uji $t$ ini dapat disimpulkan bahwa variabel keselamatan kerja $\left(\mathrm{X}_{1}\right)$ ada pengaruh yang signifikan terhadap kinerja karyawan Pada PT. Perkebunan Nusantara I PKS Pulau Tiga Aceh Tamiang.

b. Variabel kesehatan kerja $\left(\mathrm{X}_{2}\right)$ diperoleh $t_{\text {hitung }} 7,333>t_{\text {tabel }} 1,699$ sehingga Hipotesis Nol (Ho) ditolak dan Hipotesis Alternatif (Ha) diterima. Dari hasil uji t ini dapat disimpulkan bahwa variabel kesehatan kerja $\left(\mathrm{X}_{2}\right)$ ada pengaruh yang signifikan terhadap kinerja karyawan Pada PT. Perkebunan Nusantara I PKS Pulau Tiga Aceh Tamiang.

\section{Kesimpulan}

1. Hasil penelitian ini menunjukan bahwa persamaan regresi linear berganda di atas dapat dijelaskan bahwa nilai constantas sebesar 4,722 artinya jika keselamatan kerja (X1) dan kesehatan kerja (X2) dianggap constan, maka kinerja

Karyawan Pada PT. Perkebunan Nusantara I PKS Pulau Tiga Aceh Tamiang adalah 4,433 sebagai nilai constanta atau nilai variabel kinerja karyawan (Y).

2. Nilai koefisien regresi keselamatan kerja sebesar 0,280 dapat diartikan bahwa setiap $1 \%$ kenaikan kesehatan kerja yang baik $\left(\mathrm{X}_{1}\right)$ akan meningkatkan kinerja karyawan Pada PT. Perkebunan Nusantara I PKS Pulau Tiga Aceh Tamiang sebesar $28,0 \%$. Ini artinya terjadi peningkatan keselamatan kerja Pada PT. Perkebunan Nusantara I PKS Pulau Tiga Aceh Tamiang.

3. Hubungan variabel dependen dan independen yaitu masing-masing variabel keselamatan kerja $\left(\mathrm{X}_{1}\right)$ dan kesehatan kerja $\left(\mathrm{X}_{2}\right)$ terhadap kinerja karyawan Pada PT. Perkebunan Nusantara I PKS Pulau Tiga Aceh Tamiang dengan indeks korelasi sebesar 93,6\% ini berarti hubungan tersebut sangat kuat.

\section{Daftar Pustaka}

Dharma, Surya, 2010, Manajemen Kinerja, Falasafah Teori \& Penerapannya. Yokyakarta: Pustaka Pelajar 
Jurnal Sosial Humaniora Sigli (JSH)

p ISSN : 2615-3688

$e$ ISSN : 2716-0270

http : //journal.unigha.ac.id/index.php/JSH

Dessler. 2013. Manajemen Sumber Daya

Manusia. Jakarta: Salemba. Empat.

Endang Rahayu, 2014. Pengaruh Keselamatan dan Kesehatan Kerja (K3) Terjadap Kinerja Karyawan Proyek Kontruksi Pada PT. Surya Nusa Silampari Palembang. Jurnal. Vol.2

Eggy Aufal Marom, 2018. Pengaruh Keselamatan dan Kesehatan Kerja (K3) Terhadap Karyawan (Studi pada Karyawan bagian Produksi Perusahaan PT Lion Metal Works Tbk). Jurnal Fakultas Ekonomi

Ghozali, Imam. 2011. Aplikasi Analisis Multivariate Dengan Program SPSS. Cetakan Keempat. Semarang: Badan Penerbit Universitas Diponegoro.

Gujarati, $2009 . \quad$ Dasar-Dasar Ekonometrika. Jakarta: Erlangga

Hadiningrum. 2013. Faktor yang mempengaruhi Kesehatan Kerja. Bandung: Alfabeta.

Harbani Pasolong. 2010. Teori Administrasi Publik. Bandung: Alfabeta.

Hiksan Nur. 2012. Pengaruh Akuntansi Manajemen Lingkungan Terhadap Kinerja. Jakarta: Gramedia

Jokson. 2012. Manajemen Sumber Daya Manusia, Cetakan Ketiga, Jakarta: Kencana Prenada Media Group
Indah Puji. 2014. Buku Praktis Mengembangkan SDM.

Yokyakarta: Laksana.

Mangkunegara, 2010.Manajemen Sumber Daya Manusia Perusahaan. Jakarta:Refika Aditama

Manullang. $2016 . \quad$ Dasar-dasar Manajemen. Bandung: Cita Pustaka

Mahmudi, 2009.Manajemen Keuangan Daerah. Yogyakarta: Aksara

Mondy dan Noe. 2009. Manajemen Sumber Daya Manusia. Bandung: Alfabeta.

Ramli.2013. Sistem Manajemen Keselamatan \& Kesehatan. Semarang: CCAI Central Java

Ramzijah, M. (2020). Pengaruh Partisipasi Masyarakat Dan Transparansi Kebijakan Terhadap Pengawasan Anggaran Dana Desa Di Kecamatan Delima Kabupaten Pidie. Jurnal Sains Riset, 9(3), 1-8.

Ridley. 2010. Buku Ajar Kesehatan Kerja. Jakarta: EGC.

Rizky. 2011. Kinerja dan Prestasi Kerja.Salemba. Empat, Jakarta.

Robbins, P.Stephen dan Timothy A. Judge. 2012. Perilaku Organisasi. Salemba Empat. Jakarta

Sama'mur. 2015. Keselamatan Kerja dan Pencegahan Kecelakaan. Semarang: Badan Penerbit Universitas Diponegoro

Sayuti. 2013. Manajemen Kantor Praktis. Bandung: Alfabeta. 
Jurnal Sosial Humaniora Sigli (JSH)

p ISSN : 2615-3688

$e$ ISSN : 2716-0270

http : //journal.unigha.ac.id/index.php/JSH

Sedarmayanti. 2010. Sumber Daya Manusia Dan Produktivitas Kerja. Yogyakarta: Mandar Maju

Setiawan, 2011.Hubungan antara Pengetahuan dengan Sikap. Bandung: Alfabeta

Soeprihanto.2012. Penilaian Kinerja dan Pengembangan Karyawan.Jakarta : BPFE

Sugiyono, 2010.Metode Penelitian Administrasi: Pendekatan Kuantitatif,. Kualitatif, dan R\&D. Bandung: Alfabeta.
Swasto. 2011.Manajemen Sumber Daya Manusia, Malang: UB Press

Wahyu Ratna S. 2016. Manajemen Sumber Daya Manusia. Semarang: Badan Penerbit Universitas Diponegoro

Werner. 2011. Pengelolaan Sumber Daya Manusia 2, edisi kesepuluh, terjemahan.Jakarta : Salemba Empat.

Wilson Bangun. 2012. Manajemen Sumber Daya Manusia. Jakarta : Erlangga 